\title{
Prediction of Energy Consumption in the Buildings Using Multi- Layer Perceptron and Random Forest
}

\author{
Fazli Wahid ${ }^{1}$, Rozaida Ghazali ${ }^{2}$, Abdul Salam Shah ${ }^{3 *}$ and Muhammad Fayaz ${ }^{4}$ \\ ${ }^{1,2}$ Faculty of CS and IT, Universiti Tun Hussein Onn, Malaysia \\ ${ }^{3}$ SZABIST, Islamabad, Pakistan \\ ${ }^{4}$ University of Malakand, KPK, Pakistan \\ ${ }^{1}$ wahid_uomian@hotmail.com, ${ }^{2}$ rozaida@uthm.edu.my \\ 3*shahsalamss@gmail.com, ${ }^{4}$ hamaz_khan@yahoo.com
}

\begin{abstract}
The aim of the paper is to facilitate energy suppliers to make decisions for the provision of energy to different residential buildings according to their demand, which will enable the energy suppliers to manage and optimize the energy consumption in an efficient manner. In this paper, we have used Multi-layer perceptron and Random Forest to classify residential buildings according to their energy consumption. The hourly consumed historical data, of two types of buildings, have been predicted: high power and low power consumption buildings. The prediction consists of three stages: data retrieval, feature extraction, and prediction. In the data retrieval stage, the hourly consumed data based on the daily basis is retrieved from the database. In the feature extraction stage, statistical features; mean, standard deviation, skewness and kurtosis are computed from the retrieved data. In the prediction stage, Multi-Layer Perceptron and Random Forest have been used for the prediction of high power and low power consumption buildings. The hourly consumed historical data of 400 residential buildings have been used for experimentation. The data was divided into 70\% (280 buildings) training and 30\% (120 buildings) testing. The Multi-Layer Perceptron achieved $95.00 \%$ accurate result, whereas the accuracy observed by Random Forest was $90.83 \%$.
\end{abstract}

Keywords: Energy Prediction, Energy Management, Energy Optimization, Multi-layer Perceptron, Residential Buildings, Random Forest

\section{Introduction}

There are many challenges faced by modern power systems in the management of power. In order to handle these challenges, the concept of smart grid has been introduced to make the energy management system fully automatic. In order to bring enhancements in the functionalities of modern power systems, the smart grid integrates all the components of the power system including sensors, actuators, controls and computational ability [1]. For the better management of energy usage and cost, modern technologies are used by the smart grid to bring improvements in the operations, maintenance, and planning of the whole power management system [2]. Many Governments have sustained the modern communication networks to save energy and maintain environmental factors. The definitions of functions required for a smart grid to perform are provided by the US department of energy [3].

The major functions that the smart grid must be able to perform include self healing ability, motivations of consumers to be involved actively in the grid operation, resistance to attacks, and the provision of high qualitative power and enable the energy markets to manage the energy effectively according to the consumer demands. The smart grid plays

${ }^{*}$ Corresponding Author 
an important role to ensure the production of energy efficiently and according to user requirements. The energy market plays the role of a bridge for bringing together the power consumers, suppliers, and the power producers. The energy suppliers require an excellent accuracy in short-term energy forecasting including daily forecasting and hourly forecasting for getting good prices of stored energy. The percentage of residential sector energy consumption is very high the energy supplier's focuses on the residential power consumption. A large amount of power has been used by the residential sector in European countries in 2007 and since then the residential sector has got more attention as compared to the earlier statistics [4]. The power suppliers involved have to predict the next day consumption with good precision in order to obtain good prices for traded energy.

In this paper, we have used Multi-layer perceptron and Random Forest to classify residential buildings according to their energy consumption. The hourly consumed historical data, of two types of buildings, have been predicted: high power consumption buildings and low power consumption buildings. The prediction consists of three stages: data retrieval, feature extraction, and prediction.

The rest of the paper is organized as, the section 2, contain Related Work, section 3 discuss the Proposed Methodology, section 4 contain results, the conclusion of the study is provided in section 5 .

\section{Related Work}

There are many approaches existing in literature for energy consumption prediction, but the bottom up approach is the most important. In the bottom-up approach first, the energy consumed by individual home appliances is predicted. This predicted energy from individual appliances is then aggregated to forecast the total energy consumed inside the smart home. The hourly, daily, weekly and monthly energy consumption prediction for individual home appliances is also very important, but for efficient management of energy supply to the residential sector, the combined total energy consumption prediction in the smart home is very necessary. The purpose of this paper is to divide the residential building into two categories namely high power consumption residential buildings and low power residential buildings according to the energy consumed by their occupants. The prediction will help power suppliers in making good decisions related to the energy demand of customers. This prediction will also assist in smart home automation system management [5]. A three layer architecture has been presented by the authors in [6] for the smart home energy management system. These layers are called anticipative layer, local layer, and the reactive layer. Actions related to prediction e.g. price prediction, weather prediction, and energy prediction are carried out in the anticipative layer. The information related to prediction is provided to the reactive layer for its smooth functioning. The reactive layer passes this whole information to the local layer. According to the information retrieved from the reactive layer, the local layer controls the operations of all the home appliances according to the user requirements. The fourth layer of the model is responsible for the supply of energy from the outside source. In this layer, power suppliers get energy from the external market. Energy to external market comes from different sources, including hydropower plant, thermal power plant, renewable resources and nuclear power plant [7]. Different types of classifiers have been used in the literature for different types of predictions and classifications. Bayesian networks have been used by the authors in [8] and [9] for classification and prediction. The authors in [10] logistic Regression, Multilayer Perceptron and Random Forest for the energy consumption prediction. Decision tables have been used by the authors in [11] for classification. The authors in [12] presented a procedure for obtaining the patterns of consumption. The data used by the authors was obtained from residential customers. A total of 600 residential customers were observed for the pattern recognition in the consumer energy data. The 
process of pattern recognition in the residential data consists of four stages as described by the authors. For management of energy consumption and user comfort, the authors in [13] applied artificial bee colony and fuzzy logic. The aim was to minimize energy consumption and increase the occupant's comfort in the residential building. The authors in [14] applied random forest classifier to classify the residential apartments into either low power consumption apartments or high power consumption apartments whereas the authors in [15] applied $\mathrm{k}$ nearest neighbor classifier for the same purpose. The authors in [16] proposed an intelligent method of analysis for prediction and modeling for daily power consumption in residential buildings. The process presented consists of four stages namely feature extraction, outlier identification, canonical variate analysis and the classification and identification of the abnormal daily energy consumption profile. The authors in [17] applied the classification techniques to the industry sector and divided the industries in China into four different classes according to their energy consumption. The authors urge that classification is important for better energy management and future plan. The authors in [18] used a hybrid model of the artificial neural network and encoding technique for energy consumption data classification. The proposed technique can be used for the identification of illegal customers and for faster and efficient energy consumption data classification. In order to evaluate the energy consumption behavior, the authors in [19] applied hierarchical classification algorithm. The authors combined GA-based SVM with fuzzy c-means clustering for complete usage of the collected samples. The proposed approach was used for classification of normal and abnormal energy consumption behaviors. The authors in [20] applied the classification technique to commercial buildings for classification of occupants based on their energy consumption.

\section{Proposed Methodology}

A simple model of prediction uses historical data for prediction based on classification method. In this work, we have also carried out the process of prediction of power consumption which is based on the classification method. The proposed method divides the residential buildings into either low power consumption buildings or high power consumption residential buildings. The proposed method will help the power retailer in the future energy planning for residential buildings. The classification has been carried out with the Multilayer Perceptron and Random Forest, using four features. The features includes the mean, standard deviation, kurtosis and skewness. For the accuracy measurement Confusion Matrix and Kappa Statistics have been used. The proposed model is shown in Figure 1. 


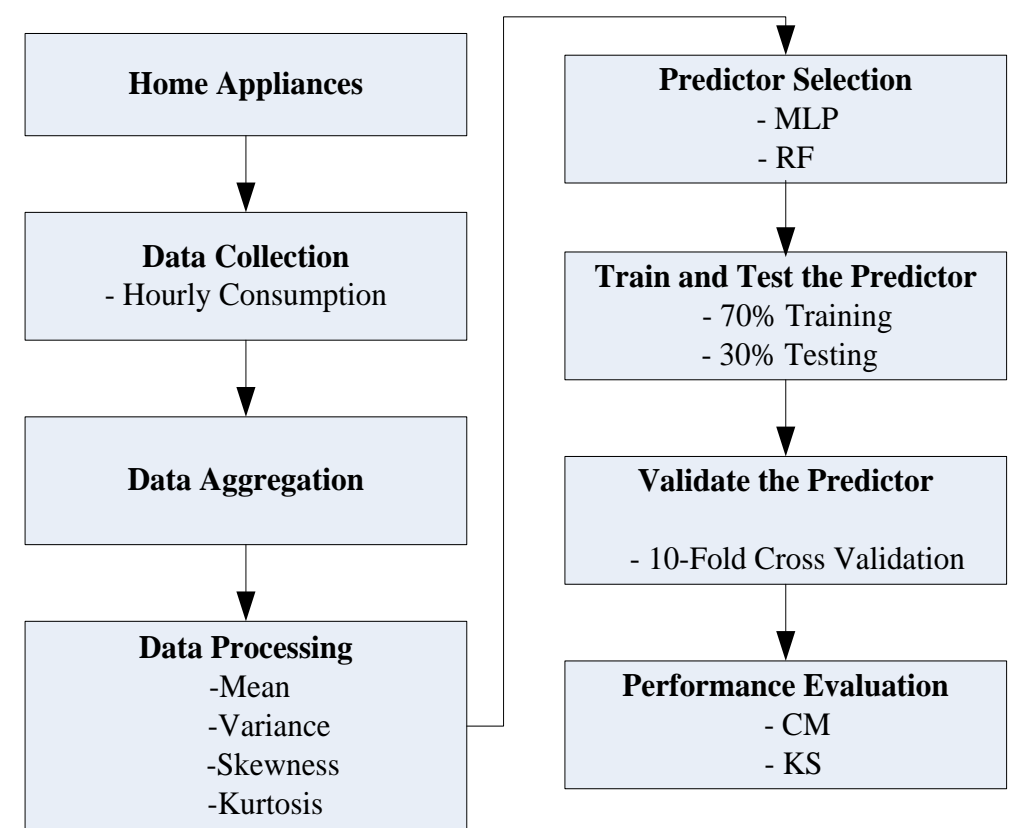

Figure 1. Proposed Methodology

\subsection{Dataset}

The hourly consumed data of 400 residential buildings have been used for analysis. Figure 2 shows the hourly consumption of the two apartments (Apartment 202, Apartment 301) we have considered for the daily energy consumption prediction. The data has been divided into $70 \%$ (280 Apartments) training and 30\% (120 Apartments) testing.

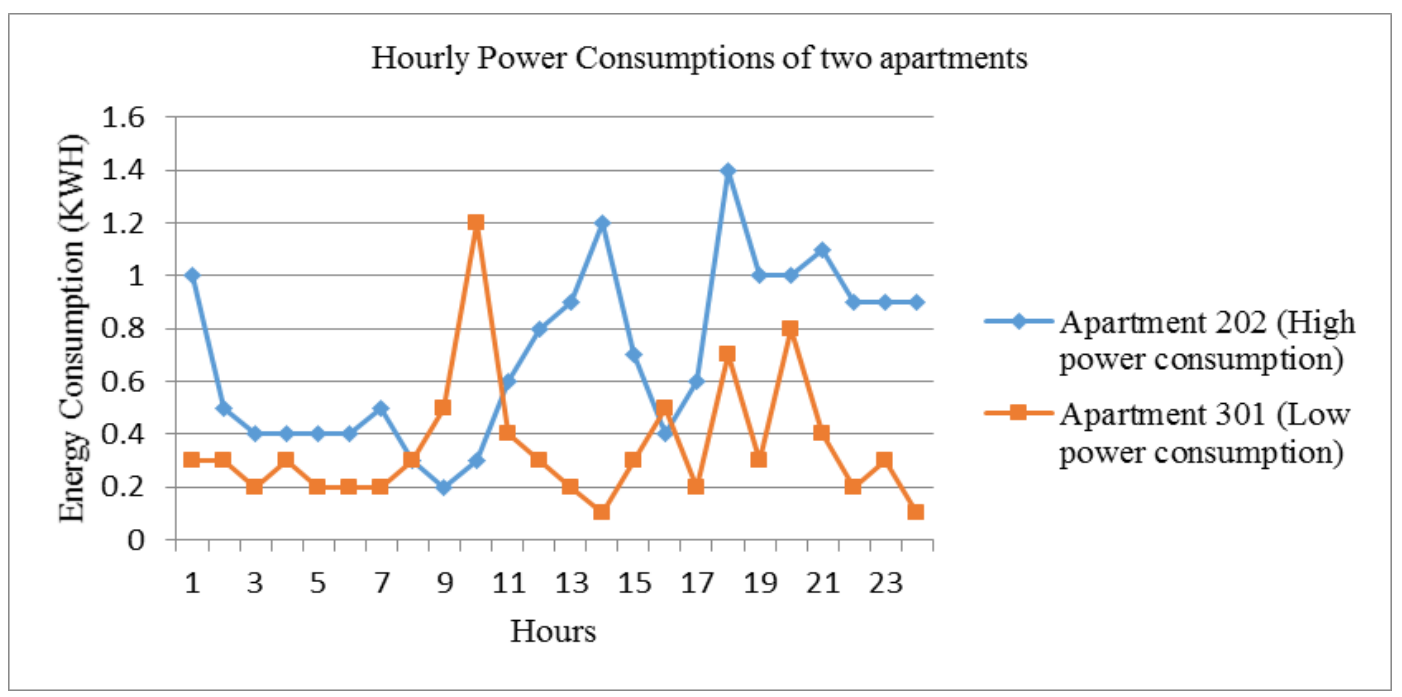

Figure 2. Low and High Power Daily Energy Consumption of Apartments

\subsection{Data Retrieval}

In this stage, the hourly consumed data on the daily basis has been retrieved from the excel database for processing. For the prediction of the apartment according to their daily energy consumption, we have historical data that contains the hourly consumed energy on the daily basis. 


\subsection{Data Processing}

The data containing hourly consumption has been selected for processing. The mean, standard deviation and skewness of the hourly consumption data has been computed. The detailed description of these features is as under:

\section{Mean}

Mean represents the average of twenty-four hours energy consumption which can be calculated by (1). M represents the mean of all the hourly consumed power over the whole day. Where ${ }^{x_{i}}$ represent power consumption over $\mathrm{i}^{\text {th }}$ hour of the day, the $\mathrm{i}$ can be $0,1,2, \ldots, 23$. N represents the total number of hours i.e. 24 .

$$
M=\frac{1}{N} \sum_{i=1}^{N} x_{i}
$$

\section{Variance}

Variance represents the variations in the hourly consumed power of the entire day which can be represented by $\mathrm{V}$ and calculated by (2).

$$
V=\frac{1}{N} \sum_{i=1}^{N}\left(x_{i}-\mu\right)^{2}
$$

\section{Skewness}

Skewness represents the asymmetry in the hourly consumed power of the entire day which can be represented by S and calculated by (3).

$$
S=\frac{1}{N} \sum_{i=1}^{N}\left(x_{i}-\mu\right)^{3}
$$

\section{Kurtosis}

Kurtosis represents the frequency of extreme hourly power consumption of home appliances of the entire day which can be represented by K and calculated by (4).

$$
K=\frac{1}{N} \sum_{i=1}^{N}\left(x_{i}-\mu\right)^{4}
$$

\subsection{Classifier for Prediction}

The hourly consumed power data is retrieved from the Excel sheet. After data retrieval during processing mean, standard deviation and skewness were calculated. The processed data is now ready for the prediction. The predictor will classify the apartments into low power or a high power consumption apartment. In this paper, we have selected MultiLayer Perceptron and Random Forest for the energy consumption prediction.

\subsubsection{Multi-layer Perceptron}

In this paper we have used, Multilayer Perceptron (MLP) having input, hidden and output layers. Perceptron is a supervised technique, which converts a set of input to output. It is a linear classifier in which the linear predictor function is responsible for the classification, which combines a set of weights with the input vector [21]. For solving computational problems, Perceptron has multiple layers connected with each other through the directed graph. Each layer is fully connected to the next layer. The training of MLP has been carried out using the back-propagation technique. The Perceptron calculates a single output from multiple inputs by making a linear combination according to input weights and nonlinear activation function computed by (5). Where w represents 
the weighted vector, $\mathrm{x}$ is input vector, $\mathrm{Y}$ represents output, $\mathrm{b}$ is biased-ness and ${ }_{\varphi}$ represent activation function.

$$
\mathrm{Y}=\mathrm{F}(\mathrm{x})={ }_{\varphi}\left(\sum_{j=1}^{n} w_{j} x_{j}+b\right)={ }_{\varphi}\left(\mathrm{w}^{\mathrm{T}} \mathrm{x}+\mathrm{b}\right)
$$

Figure 3 contains the architecture of a single perceptron. The architecture of the multilayer perceptron with three layers is shown in Figure 4.

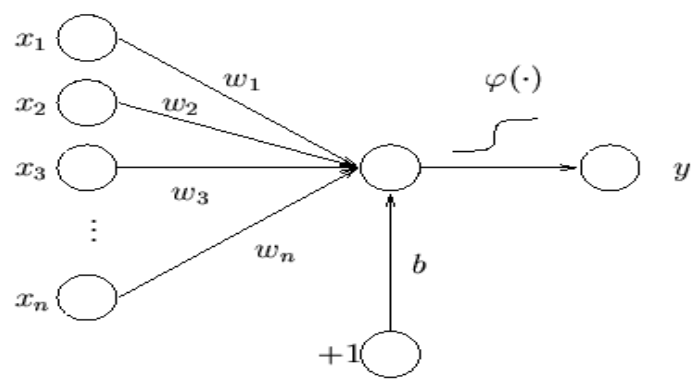

Figure 3. Single Perceptron Architecture

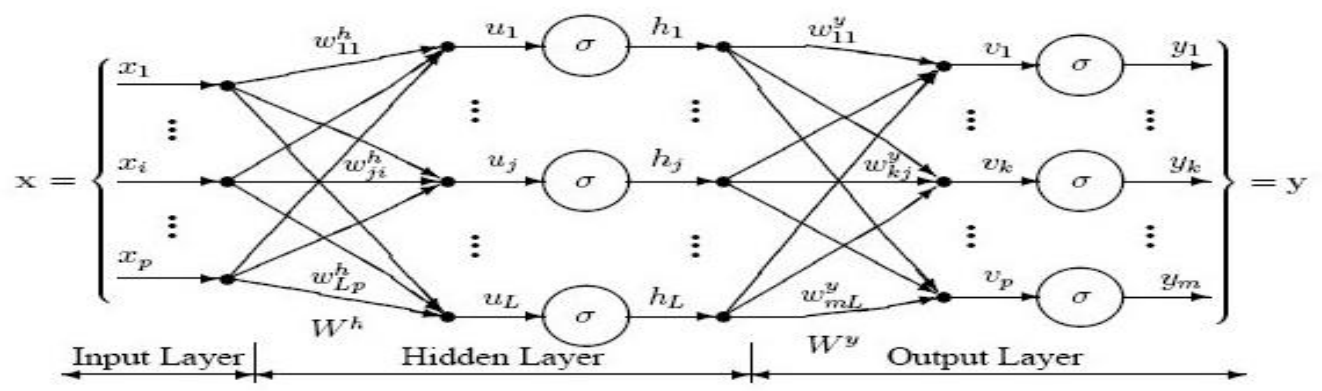

Figure 4. Multi-layer Perceptron with Input, Hidden and Output Layers

\subsubsection{Random Forest (RF)}

The second classifier we have used is the Random Forest which is an ensemble classifier applied in pattern recognition and classification [22]. It can be considered as a classifier containing different classification methods or one method having several parameters. Suppose we have a learning set $\mathrm{L}=((\mathrm{m} 1, \mathrm{n} 1), . .,(\mathrm{mi}, \mathrm{ni}))$ with i vectors having $m \in X$ and $n \in Y$ where $X$ represents the observations and $Y$ represents the class labels. For the prediction of a class, the classifier performs the mapping $\mathrm{X} \rightarrow \mathrm{Y}$. Each individual tree in the forest classifies the new instance.

\subsection{Performance Evaluation}

The residential buildings are classified into low and high power consumption buildings according to their power usage. The prediction has been carried out with Multi-Layer Perceptron and Random Forest. For the measurement of the accuracy of the predictors, Confusion Matrix and Kappa Statistics (KS) were used.

The experiments have been carried out using Weka 3.7 and MATLAB R2010 on a system having Intel (R) Core (TM) 2 Quad CPU with 3.25 GB of RAM. MATLAB has been used for feature extraction whereas Weka has been used for classification. The independent variables of both the classifiers are mean, variance, skewness, and Kurtosis of 24 hours hourly energy consumption and the dependent variable is the class of the residential building which takes 0 or 1 value for the low power residential building and 
the high power residential building, respectively. The whole dataset has been divided into $70 \%$ training and $30 \%$ testing data set. In order to generalize the algorithm, 10-Fold crossvalidation has been applied.

\subsubsection{Confusion Matrix (CM)}

The confusion matrix is a table that shows the predicted and the actual results of the prediction system. The entries in the matrix are used for the evaluation of the prediction system. A confusion matrix for the two class predictor is shown in the Table1. The predicted classes can be 'positive' or 'negative' instances, which means that the apartment using the power will belong to the high power consumption apartment or the low power consumption apartment. In this study, the entries in the confusion matrix have the following meaning.

1. A represents the number of correct predictions for negative instances.

2. B represents the number of incorrect predictions for positive instances.

3. C represents the number of incorrect predictions for negative instances.

4. D represents the number of correct predictions for positive instances.

Table 1. Confusion Matrix for the Two Class Predictor

\begin{tabular}{|c|c|c|}
\hline \multirow{2}{*}{ Actual } & \multicolumn{2}{|c|}{ Predicted } \\
\cline { 2 - 3 } & Negative & Positive \\
\cline { 2 - 3 } & $\mathrm{A}$ & $\mathrm{B}$ \\
\cline { 2 - 3 } & $\mathrm{C}$ & $\mathrm{D}$ \\
\hline
\end{tabular}

The accuracy of the prediction is the proportion of the total number of correct predictions the same can be and is calculated using (6).

$$
\text { Accuracy }=\frac{A+D}{A+B+C+D}
$$

\subsubsection{Kappa Statistics (KS)}

The agreement between observed and predicted values of the data set can be measured using Kappa statistics. The Kappa Statistics has the values between -1 and 1. The classification capability of a classifier improves when the value of Kappa Statistics approaches to 1 and the same degrades when the value approaches to -1. Kappa Statistics can be computed using (7). Where P0 is the total probability of agreement, PC is the hypothetical probability of the chance agreement.

$$
\mathrm{KS}=\frac{P 0-P C}{1-P C}
$$

\section{Results}

The experimental results for multi-layer perceptron are shown in the following table 2 . The prediction accuracy and Kappa Statistics of the random forest tree for energy consumption apartments are shown in the table 3 both for percentage split and the crossvalidation. 
Table 2. Prediction Accuracy and Kappa Statistics of MLP

\begin{tabular}{|c|c|c|c|c|c|c|c|}
\hline \multicolumn{4}{|c|}{$\begin{array}{c}\text { Percentage split on testing data set } \\
\text { (70\% training) }\end{array}$} & \multicolumn{4}{|c|}{ 10-Fold Cross Validation } \\
\hline \multicolumn{4}{|c|}{$\begin{array}{c}\text { High power consumption apartments' } \\
\text { statistics }\end{array}$} & \multicolumn{4}{|c|}{$\begin{array}{c}\text { High power consumption apartments' } \\
\text { accuracy }\end{array}$} \\
\hline $\begin{array}{c}\text { Total } \\
\text { Apartments }\end{array}$ & $\begin{array}{l}\text { Correctly } \\
\text { Predicted }\end{array}$ & $\begin{array}{l}\text { Incorrectly } \\
\text { Predicted }\end{array}$ & Accuracy & $\begin{array}{c}\text { Total } \\
\text { Apartments }\end{array}$ & $\begin{array}{l}\text { Correctly } \\
\text { Predicted }\end{array}$ & $\begin{array}{l}\text { Incorrectly } \\
\text { Predicted }\end{array}$ & Accuracy \\
\hline 70 & 69 & 1 & $98.57 \%$ & 280 & 260 & 20 & $92.85 \%$ \\
\hline \multicolumn{4}{|c|}{$\begin{array}{c}\text { Low power consumption apartments' } \\
\text { statistics }\end{array}$} & \multicolumn{4}{|c|}{$\begin{array}{c}\text { Low power consumption apartments' } \\
\text { accuracy }\end{array}$} \\
\hline $\begin{array}{c}\text { Total } \\
\text { Apartments }\end{array}$ & $\begin{array}{l}\text { Correctly } \\
\text { Predicted }\end{array}$ & $\begin{array}{l}\text { Incorrectly } \\
\text { Predicted }\end{array}$ & Accuracy & $\begin{array}{c}\text { Total } \\
\text { Apartments }\end{array}$ & $\begin{array}{l}\text { Correctly } \\
\text { Predicted }\end{array}$ & $\begin{array}{l}\text { Incorrectly } \\
\text { Predicted }\end{array}$ & Accuracy \\
\hline 50 & 45 & 5 & $90.00 \%$ & 120 & 111 & 9 & $92.50 \%$ \\
\hline \multicolumn{4}{|c|}{ Overall Accuracy } & \multicolumn{4}{|c|}{ Overall Accuracy } \\
\hline $\begin{array}{c}\text { Total } \\
\text { Apartments }\end{array}$ & $\begin{array}{l}\text { Correctly } \\
\text { Predicted }\end{array}$ & $\begin{array}{l}\text { Incorrectly } \\
\text { Predicted }\end{array}$ & Accuracy & $\begin{array}{c}\text { Total } \\
\text { Apartments }\end{array}$ & $\begin{array}{l}\text { Correctly } \\
\text { Predicted }\end{array}$ & $\begin{array}{l}\text { Incorrectly } \\
\text { Predicted }\end{array}$ & Accuracy \\
\hline 120 & 114 & 6 & $95.00 \%$ & 400 & 371 & 29 & $92.75 \%$ \\
\hline \multicolumn{3}{|c|}{ Kappa Statistics (KS) } & 0.895 & \multicolumn{3}{|c|}{ Kappa Statistics (KS) } & 0.874 \\
\hline
\end{tabular}

Table 3. Prediction Accuracy and Kappa Statistics of RF

\begin{tabular}{|c|c|c|c|c|c|c|c|}
\hline \multicolumn{4}{|c|}{$\begin{array}{c}\text { Percentage Split on Testing Data } \\
\text { (70\% Training) }\end{array}$} & \multicolumn{4}{|c|}{10 Fold Cross Validation } \\
\hline \multicolumn{4}{|c|}{$\begin{array}{c}\text { High power consumption apartments' } \\
\text { statistics }\end{array}$} & \multicolumn{4}{|c|}{$\begin{array}{c}\text { High power consumption apartments' } \\
\text { accuracy }\end{array}$} \\
\hline $\begin{array}{c}\text { Total } \\
\text { Apartments }\end{array}$ & $\begin{array}{l}\text { Correctly } \\
\text { Predicted }\end{array}$ & $\begin{array}{l}\text { Incorrectly } \\
\text { Predicted }\end{array}$ & Accuracy & $\begin{array}{c}\text { Total } \\
\text { Apartments }\end{array}$ & $\begin{array}{l}\text { Correctly } \\
\text { Predicted }\end{array}$ & $\begin{array}{l}\text { Incorrectly } \\
\text { Predicted }\end{array}$ & Accuracy \\
\hline 70 & 67 & 3 & $95.71 \%$ & 280 & 247 & 33 & $88.21 \%$ \\
\hline \multicolumn{4}{|c|}{$\begin{array}{c}\text { Low power consumption apartments' } \\
\text { statistics }\end{array}$} & \multicolumn{4}{|c|}{$\begin{array}{l}\text { Low power consumption apartments' } \\
\text { accuracy }\end{array}$} \\
\hline $\begin{array}{c}\text { Total } \\
\text { Apartments }\end{array}$ & $\begin{array}{l}\text { Correctly } \\
\text { Predicted }\end{array}$ & $\begin{array}{l}\text { Incorrectly } \\
\text { Predicted }\end{array}$ & Accuracy & $\begin{array}{c}\text { Total } \\
\text { Apartments }\end{array}$ & $\begin{array}{l}\text { Correctly } \\
\text { Predicted }\end{array}$ & $\begin{array}{l}\text { Incorrectly } \\
\text { Predicted }\end{array}$ & Accuracy \\
\hline 50 & 42 & 8 & $84 \%$ & 120 & 104 & 16 & $86.66 \%$ \\
\hline \multicolumn{4}{|c|}{ Overall Accuracy } & \multicolumn{4}{|c|}{ Overall Accuracy } \\
\hline $\begin{array}{c}\text { Total } \\
\text { Apartments }\end{array}$ & $\begin{array}{l}\text { Correctly } \\
\text { Predicted }\end{array}$ & $\begin{array}{l}\text { Incorrectly } \\
\text { Predicted }\end{array}$ & Accuracy & $\begin{array}{c}\text { Total } \\
\text { Apartments }\end{array}$ & $\begin{array}{l}\text { Correctly } \\
\text { Predicted }\end{array}$ & $\begin{array}{l}\text { Incorrectly } \\
\text { Predicted }\end{array}$ & Accuracy \\
\hline 120 & 109 & 11 & $90.83 \%$ & 400 & 351 & 49 & $87.75 \%$ \\
\hline \multicolumn{3}{|c|}{ Kappa Statistics (KS) } & 0.859 & \multicolumn{3}{|c|}{ Kappa Statistics (KS) } & 0.815 \\
\hline
\end{tabular}

\section{Conclusion}

The main focus of the paper is to construct a model for the prediction of energy consumption of residential apartments which will help the system to organize energy production and consumption. It will also help to decide whether energy consumption of residential buildings will be high or low (energy management). This will also be useful for the energy management system in fixing the prices of energy according to consumption of different apartments. The process of prediction consists of three stages; data retrieval, feature extraction, and prediction. Multi-Layer Perceptron and Random Forest have been used for the prediction of high power and low power consumption apartments. The MLP has performed better than the Random Forest. 


\section{References}

[1] C. W. Gellings, "The smart grid: enabling energy efficiency and demand response", The Fairmont Press, Inc., (2009).

[2] A. Ipakchi and F. Albuyeh, "Grid of the future," Power and Energy Magazine, IEEE, vol. 7, (2009), pp. 52-62.

[3] M. C. Williams, J. P. Strakey, and W. A. Surdoval, "The US department of energy, office of fossil energy stationary fuel cell program," Journal of Power Sources, vol. 143, (2005), pp. 191-196.

[4] D. Tren, "EU energy and transport in figuresâ€"Statistical pocketbook 2009, Directorate-General for Energy and Transport," Office for Official Publications of the European Communities, Luxemburg, (2009).

[5] D. L. Ha, S. A. Ploix, E. Zamai, and M. Jacomino, "Realtimes dynamic optimization for demand-side load management," International Journal of Management Science and Engineering Management, vol. 3, (2008), pp. 243-252.

[6] K. Basu, L. Hawarah, N. Arghira, H. Joumaa, and S. Ploix, "A prediction system for home appliance usage," Energy and Buildings, vol. 67, (2013), pp. 668-679.

[7] N. Arghira, L. Hawarah, S. P. Ploix, and M. Jacomino, "Prediction of appliances energy use in smart homes," Energy, vol. 48, no.1, (2012), pp. 128-134.

[8] L. Hawarah, M. Jacomino, and S. P. Ploix, "Smart Home-From User's Behavior to Prediction of Energy Consumption," ICINCO 2010, Proceedings of the 7th International Conference on Informatics in Control, Automation and Robotics, Volume 1, Funchal, Madeira, Portugal, June 15-18, (2010).

[9] I. H. Witten and E. Frank, Data Mining: Practical machine learning tools and techniques: Morgan Kaufmann, (2005).

[10] Wahid, F., R.Ghazali, M.Fayaz and A.S.Shah, "A simple and Easy Approach for Home Appliances Energy Consumption Prediction in Smart Homes Using Machine Learning Techniques", Journal of Applied Environmental and Biological Sciences, vol. 7, no.3, (2017), pp.108-119.

[11] R. Kohavi, "The power of decision tables," in Machine Learning: ECML-95: Springer, (1995), pp. 174189.

[12] Niembro, G. R., and R. D. Acosta, "A Methodology to Classify Residential Customers by their pattern of Consumption", In Power Engineering Society Summer Meeting, 1999. IEEE, vol. 1, (1999), pp. 226231.

[13] Wahid, F., and D.H. Kim, "Prediction Methodology of Energy Consumption Based on Random Forest Classifier in Korean Residential Apartments", Advanced Science and Technology Letters, vol.120, (GST 2015), (2015), pp.654-687.

[14] Wahid, F., and D. H. Kim, "A Prediction Approach for Demand Analysis of Energy Consumption Using K-Nearest Neighbor in Residential Buildings", International Journal of Smart Home, vol. 10, no.2, (2016), pp.97-108.

[15] Wahid, F., and D. H. Kim, "An Efficient Approach for Energy Consumption Optimization and Management in Residential Building Using Artificial Bee Colony and Fuzzy Logic", Mathematical Problems in Engineering, vol. 2016, Article ID 9104735, 13 pages, (2016).

[16] Li, X., Bowers, C.P. and T. Schnier, "Classification of energy consumption in buildings with outlier detection", IEEE Transactions on Industrial Electronics, vol. 57, no. 11, (2010), pp.3639-3644

[17] Liu L., H. Zhang, and Y. Zhang, "Energy consumption and potential of energy-saving of China based on industry classifications", 2011 International Conference on Remote Sensing, Environment and Transportation Engineering (RSETE), (2011), pp. 293-299.

[18] Depuru, S.S.S.R., L. Wang, V. Devabhaktuni, and P. Nelapati, "A Hybrid Neural Network Model and Encoding Technique for Enhanced Classification of Energy Consumption Data", In 2011 IEEE Power and Energy Society General Meeting, (2011), pp. 1-8. IEEE.

[19] $\mathrm{Bu}, \mathrm{Li}, \mathrm{D}$. Zhao, Y. Liu, and Q. Guan, "A hierarchical classification algorithm for evaluating energy consumption behaviors", International Joint Conference on Neural Networks (IJCNN), (2014), pp. 14611466. IEEE.

[20] Gulbinas, R., A. Khosrowpour, and J. Taylor, "Segmentation and Classification of Commercial Building Occupants by Energy-use Efficiency and Predictability", IEEE Transactions on Smart Grid, vol.6, no.3, (2015), pp.1414-1424.

[21] Wahid, F., R.Ghazali, M.Fayaz and A.S.Shah, "Statistical Features Based Approach (SFBA) for Hourly Energy Consumption Prediction Using Neural Network", International Journal of Information Technology and Computer Science (IJITCS), (2017), In Press.

[22] Breiman, L., "Random forests," Machine learning, vol. 45, no.1, (2001), pp. 5-32. 


\section{Authors}

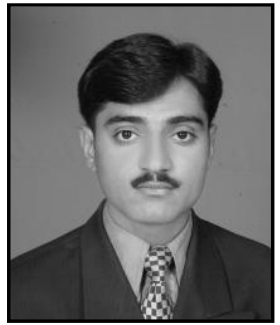

Fazli Wahid, received BS in Computer Science from University of Malakand, Pakistan in 2006, and MS in Computer Science from SZABIST, Islamabad, Pakistan in 2015. He is currently perusing $\mathrm{Ph} . \mathrm{D}$. in Computer Science at Universiti Tun Hussein Onn Malaysia (UTHM).

His area of interest are energy consumption prediction, optimization, and management using multilayer perceptron, Artificial Bee Colony, Ant Colony and other Machine Learning Techniques.

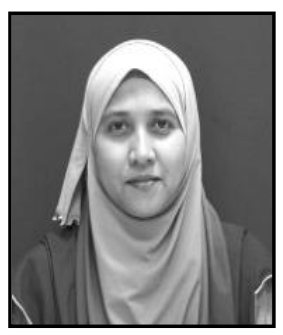

Rozaida Ghazali is currently an Associate Professor at the Faculty of Computer Science and Information Technology, Universiti Tun Hussein Onn Malaysia (UTHM). She graduated with a Ph.D. degree in Higher Order Neural Networks from the School of Computing and Mathematical Sciences at Liverpool John Moores University, United Kingdom in 2007.

Earlier, in 2003 she completed her M.Sc. degree in Computer Science from Universiti Teknologi Malaysia (UTM). She received her B.Sc. (Hons) degree in Computer Science from Universiti Sains Malaysia (USM) in 1997. In 2001, Rozaida joined the academic staff in UTHM. Her research area includes neural networks, swarm intelligence, optimization, data mining, time series prediction, and data classification. She has successfully supervised a number of $\mathrm{PhD}$ and master students and published more than 100 articles in various international journals and conference proceedings. She acts as a reviewer for various journals and conferences. She has also served as a conference chair, and as a technical committee for numerous international conferences.

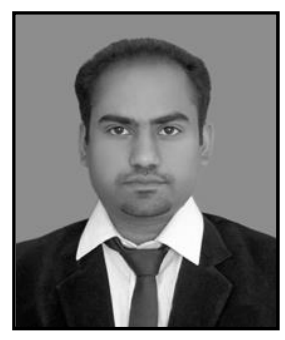

Abdul Salam Shah, has recently completed specialization in Management Information System (MIS) from Virtual University of Pakistan. He has completed MS degree in Computer Science from SZABIST, Islamabad, Pakistan in 2016. He did his BS degree in Computer Science from Isra University Hyderabad, Sindh Pakistan in 2012. In addition to his degree, he has completed short courses and diploma certificates in Databases, Machine Learning, Artificial Intelligence, Cybercrime, Cybersecurity, Networking, and Software Engineering. He has published articles in various journals of high repute. He is a young professional and he started his career in the Ministry of Planning, Development and Reforms, Islamabad Pakistan. His research area includes Machine Learning, Artificial Intelligence, Digital Image Processing and Data Mining.

Mr. Shah has contributed in a book titled "Research Methodologies; an Islamic perspectives," International Islamic University Malaysia, November, 2015.

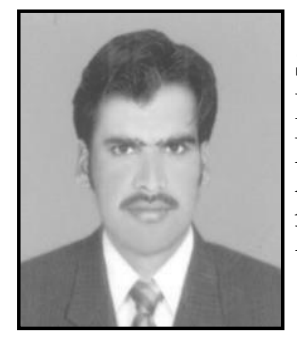

Muhammad Fayaz, is currently perusing Ph.D. in Computer Science. He received MS in Computer Science from SZABIST, Islamabad, Pakistan in 2014. He did MSC from the University of Malakand, KPK, Pakistan in 2011. His areas of interest are NP problems, Approximation Algorithms, Image Processing, and Pattern Recognition. 